\title{
Surface-Induced Changes in the Thermochromic Transformation of an Ionic Liquid Cobalt Thiocyanate Complex
}

\author{
Benjamin May, Michael Hönle, Bettina Heller, Francesco Greco, Radha Bhuin, Hans-Peter Steinrück, ${ }^{(0)}$ \\ and Florian Maier*(1)
}

Lehrstuhl Physikalische Chemie II, FAU Universität Erlangen-Nürnberg, Egerlandstraße 3, D-91058 Erlangen, Germany

Supporting Information

ABSTRACT: We demonstrate that a thermodynamic complex equilibrium within an ionic liquid film can be significantly influenced by the presence of the liquid-vacuum interface. Using surfacesensitive X-ray photoelectron spectroscopy, we find that the temperature-driven transition from the blue-colored tetrahedral $\left[\mathrm{Co}(\mathrm{II})(\mathrm{NCS})_{4}\right]^{2-}$ to the red-colored octahedral [Co(II) (NCS) $\left.{ }_{6}\right]^{4-}$ complex already occurs within the outermost nanometers at around $+4{ }^{\circ} \mathrm{C}$ as compared with $-25{ }^{\circ} \mathrm{C}$ in the bulk. This thermochromic transformation in the near-surface region goes along with a loss in preferential surface orientation of free $[\mathrm{SCN}]^{-}$anions and with a pronounced decrease in the complex density; both effects are attributed to the formation of a weakly bound solvation shell around the $\left[\mathrm{Co}(\mathrm{II})(\mathrm{NCS})_{6}\right]^{4-}$ anion, leading to an effective complex dilution. Our results are not only relevant for high-surface area thin film systems, such as in sensor and catalysis applications, but also shed light on the role of ionic liquid surfaces in particular and liquid surfaces in general.

$\mathrm{W}$ hen applying thin liquid films, for example, in sensor, chromatography, lubrication, and coating technologies, the interface of the liquid film to its environment becomes increasingly relevant when the films are becoming thinner and thinner. For such systems, it is important to know whether and to what extent the film properties close to the interface are different from those in the bulk.

One prominent example of thin liquid film applications is the new and very successful concept of "Supported Ionic Liquid Phase" (SILP) catalysis. ${ }^{1}$ In SILP, a high-surface area solid substrate is covered with a thin ionic liquid (IL) film, which typically contains a dissolved transition metal (TM) complex $^{2-5}$ as catalytically active species, with the IL acting as a nonvolatile solvent for both the reactants and the complex. In addition to their solvent character, ILs also have the potential for providing ionic ligands for the desired complex with concentrations far above those achieved in traditional molecular solvents reducing potential ligand exchange by other solvent molecules. To optimize such high-surface area systems employing dissolved TM complexes, a full understanding of the near-surface region and possible differences of the dissolved complex to its bulk behavior is highly desired, which requires surface-sensitive analytics.

Because of their extremely low vapor pressure, the nearsurface region of ILs can, in contrast with most of the commonly used solvents, be studied using the powerful techniques of ultrahigh vacuum (UHV)-based surface science such as X-ray photoelectron spectroscopy (XPS). While XPS studies on solid surfaces are restricted to the static properties of transition metal complexes, ${ }^{6-8}$ investigations in the liquid state also allow for studying dynamical phenomena, ${ }^{9-14}$ that is, timeor temperature-dependent processes. Because of its inherent surface sensitivity, XPS provides information on changes of chemical states within the topmost $1-10 \mathrm{~nm}$. This near-surface region can indeed behave quite differently from the bulk, as was recently demonstrated in an XPS study for $\mathrm{CO}_{2}$ capture using amine-functionalized ILs: The specific $\mathrm{CO}_{2}$-amine chemistry found in the topmost IL layers leads to a much higher uptake capacity in the near-surface region compared with the bulk one. $^{15}$

Herein, we apply XPS for the first time to a thermodynamic metal complex equilibrium based on ILs containing the doubly negatively charged tetrathiocyanatocobaltate(II) ([Co$\left.\left.(\mathrm{NCS})_{4}\right]^{2-}\right)$ as the anion, a system introduced by Peppel et al. ${ }^{16}$ Osborne et al. ${ }^{17}$ reported thermochromatic behavior of this anion formed by dissolving cobalt(II) isothiocyanate $\left(\mathrm{Co}(\mathrm{NCS})_{2}\right)$ in the IL 1-ethyl-3-methylimidazolium thiocyanate $\left(\left[\mathrm{C}_{2} \mathrm{C}_{1} \mathrm{Im}\right][\mathrm{SCN}]\right)$. At room temperature, the complex equilibrium in Scheme 1 lies on the left side, as witnessed by the deep blue color of the tetrahedrally coordinated cobalt anion. Cooling shifts the equilibrium to the right, toward the octahedrally coordinated complex: At around $-40{ }^{\circ} \mathrm{C}$, the

Received: January 19, 2017

Accepted: February 17, 2017

Published: February 17, 2017 
Scheme 1. Investigated Thermochromic Complex Equilibrium (Top) Represented by the Ionic Liquids IL-3 and IL-4 (Middle) Employing a 3:1 Molar Mixture of IL-1 and IL-2 (Bottom $)^{a}$

$$
2[\mathrm{SCN}]^{-}+\underset{\text { bright blue }}{\left[\mathrm{Co}(\mathrm{III})(\mathrm{NCS})_{4}\right]^{--}} \underset{\text { heating }}{\stackrel{\text { cooling }}{\rightleftharpoons}} \underset{\text { red }}{\left[\mathrm{Co}\left(\mathrm{III}(\mathrm{NCS})_{6}\right]^{4-}\right.}
$$

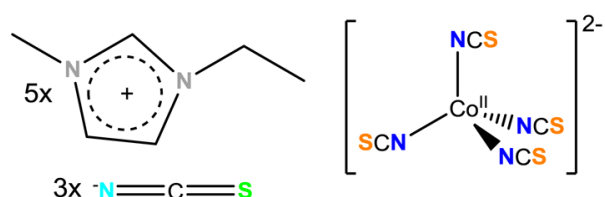

IL-3

$=3 \times I L-1+I L-2$

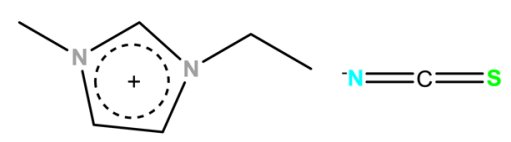

IL-1

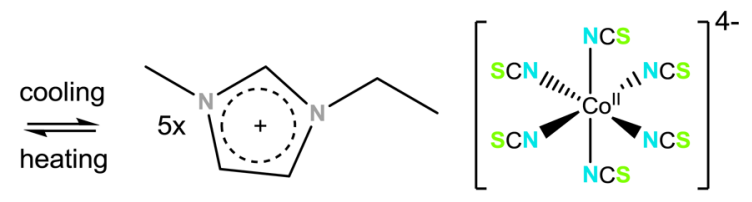

$-\mathrm{N}=\mathrm{C}=\mathrm{S}$

IL-4

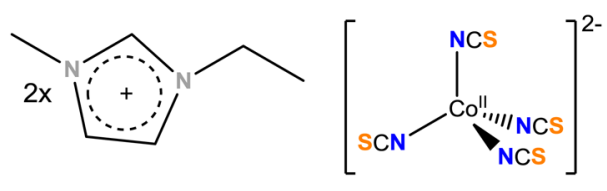

IL-2

${ }^{a}$ Colored atoms with their specific binding energy values shown in Figure 1 and discussed in the text: $\mathrm{N}$ 1s imidazolium (grey) $=401.8 \mathrm{eV} ; \mathrm{N} 1 \mathrm{~s}$ free $[\mathrm{SCN}]^{-}$(bright blue $)=397.8 \mathrm{eV} \approx \mathrm{N} 1 \mathrm{~s}\left[\mathrm{Co}(\mathrm{NCS})_{6}\right]^{4-} ; \mathrm{N} \mathrm{1s}\left[\mathrm{Co}(\mathrm{NCS})_{4}\right]^{2-}($ dark blue $)=398.5 \mathrm{eV} ; \mathrm{S} 2 \mathrm{p}_{3 / 2}$ free $[\mathrm{SCN}]^{-}($green $)=162.2 \mathrm{eV} \approx \mathrm{S}$ $2 \mathrm{p}_{3 / 2}\left[\mathrm{Co}(\mathrm{NCS})_{6}\right]^{4-} ; \mathrm{S} 2 \mathrm{p}_{3 / 2}\left[\mathrm{Co}(\mathrm{NCS})_{4}\right]^{2-}$ (orange) $=162.9 \mathrm{eV}$.

octahedral red form in the bulk dominates, as shown by UVvis and IR absorption spectroscopy. ${ }^{17}$ It should be noted that the transition between both complexes goes not only along with changes in optical absorption but also with changes in magnetic properties ${ }^{17}$ and conductivity. ${ }^{18}$ Very recently, it was also demonstrated that the equilibrium is shifted to the right by applying external pressure. ${ }^{18}$ These characteristics make this complex system very interesting for sensor applications.

To investigate the dynamics of the above equilibrium, we employed a mixture of the IL di(1-ethyl-3-methylimidazolium) tetrathiocyanatocobaltate(II) $\left(\left[\mathrm{C}_{2} \mathrm{C}_{1} \mathrm{Im}\right]_{2}\left[\mathrm{Co}(\mathrm{II})(\mathrm{NCS})_{4}\right]\right.$, IL2) with an excess of 1-ethyl-3-methylimidazolium thiocyanate $\left(\left[\mathrm{C}_{2} \mathrm{C}_{1} \mathrm{Im}\right][\mathrm{SCN}], \mathrm{IL}-1\right)$ in a 1:3 molar ratio, forming a new IL with nominal composition $\left[\mathrm{C}_{2} \mathrm{C}_{1} \mathrm{Im}\right]_{5}\left[\mathrm{Co}(\mathrm{II})(\mathrm{NCS})_{4}\right][\mathrm{SCN}]_{3}$ (IL-3; see also Scheme 1). (Note that thiocyanate acting as ligand is denoted in the following as " $[\mathrm{NCS}]^{-}$", because the coordination occurs via the negatively charged nitrogen end to the $\mathrm{Co}^{2+}$ center, ${ }^{16}$ whereas free thiocyanate anions are labeled as " $[\mathrm{SCN}]^{-") \text {. }}$

As a first step, we studied the thermochromic behavior of the bulk of the mixture IL-3 in a simple temperature experiment (see Figure S1 of the Supporting Information, SI). Indeed, a color change from blue to red occurred as a function of temperature over a similar temperature range as that reported by Osborne et al. ${ }^{17}$ (full blue: $T \geq-10{ }^{\circ} \mathrm{C}$, full red: $T \leq-40$ ${ }^{\circ} \mathrm{C}$, midtransition temperature around $-25{ }^{\circ} \mathrm{C}$; see Figure $\mathrm{S} 2$ of the SI). Thereby, the mixture IL-3 $\left(\left[\mathrm{C}_{2} \mathrm{C}_{1} \mathrm{Im}\right]_{2}^{+}\left[\mathrm{Co}(\mathrm{NCS})_{4}\right]^{2-}\right.$ $\left.+3\left[\mathrm{C}_{2} \mathrm{C}_{1} \mathrm{Im}\right]^{+}[\mathrm{SCN}]^{-}\right)$transforms to a new mixture IL-4 $\left(\left[\mathrm{C}_{2} \mathrm{C}_{1} \mathrm{Im}\right]^{+}{ }_{4}\left[\mathrm{Co}(\mathrm{II})(\mathrm{NCS})_{6}\right]^{4-}+\left[\mathrm{C}_{2} \mathrm{C}_{1} \mathrm{Im}\right]^{+}[\mathrm{SCN}]^{-}\right)$. Notably, the latter has an excess of one free $[\mathrm{SCN}]^{-}$anion per formed octahedral complex, as also shown in Scheme 1.

To search for possible differences of the bulk behavior and the behavior in the near-surface region, we performed a detailed XPS study. The neat ILs IL-1 and IL-2 and the mixture IL-3 were each placed on sample holders and introduced to our UHV system and temperature-dependent spectra were taken, starting from room temperature, down to $-75^{\circ} \mathrm{C}$. As it will be shown, the complex transition occurs at considerable higher temperatures in the near-surface region (which is probed by XPS with a maximum information depth of $\sim 10 \mathrm{~nm}$ ) than in the bulk.

The thiocyanate signals of the cobalt-coordinated ligands and of the free anions can be easily monitored in the N 1s and S $2 p$ region; the corresponding carbon signal is superimposed on the imidazolium ring carbon signal and could not be separated. In Figure 1, the room temperature $\left(24^{\circ} \mathrm{C}\right) \mathrm{N} 1 \mathrm{~s}$ and $\mathrm{S} 2 \mathrm{p}$ spectra taken in $0^{\circ}$ emission are shown in comparison with the spectra recorded at $-10{ }^{\circ} \mathrm{C}$.

For IL-1 and IL-2, the binding energies of the thiocyanate nitrogen in free $[\mathrm{SCN}]^{-}$and in the cobalt-bound $[\mathrm{NCS}]^{-}$ ligands, at 397.8 and $398.5 \mathrm{eV}$, respectively, are well separated from the $\mathrm{N}$ 1s signal originating from the positively charged imidazolium ring at $401.8 \mathrm{eV}$. The corresponding spin-orbit split S $2 \mathrm{p}$ signals of IL-1 are found at lower binding energy (162.2 eV, S 2 $\mathrm{p}_{3 / 2}$ component) compared with IL-2 (162.9 eV).

To gain information on the composition/orientation at the IL/vacuum interface, we also performed simultaneous ARXPS measurements (see Figure S3) at $0^{\circ}$ (bulk-sensitive) and $80^{\circ}$ (surface-sensitive) electron emission angle for the three $\mathrm{IL}$ samples above and below the bulk complex transition temperature $\left(24,-10\right.$, and $\left.-30{ }^{\circ} \mathrm{C}\right)$. For IL- 1 , the spectra show no change with temperature but clearly demonstrate a preferential orientation of the free thiocyanate anions at the surface: When changing from 0 to $80^{\circ}$, the anion $S 2 p$ intensity increases by $\sim 25 \%$ and the anion $\mathrm{N} 1 \mathrm{~s}$ peak at $397.8 \mathrm{eV}$ increases by only $5-10 \%$ (both relative to the imidazolium $\mathrm{N}$ $1 \mathrm{~s}$ peak at $401.8 \mathrm{eV}$ ). This indicates that the linear free thiocyanate anions in IL-1 are preferentially oriented within the outermost surface layer, with the sulfur end pointing toward the vacuum and the nitrogen end pointing toward the bulk. Similar orientation effects at surfaces have been reported for other IL systems: In most cases, noncharged moieties such as long alkyl chains attached to ionic head groups as well as $\mathrm{CF}_{3}$ groups of perfluorated anions are consistently reported to point preferentially toward the vacuum side. ${ }^{13}$ For [SCN]-based ILs, such strong surface orientation effects have not yet been 


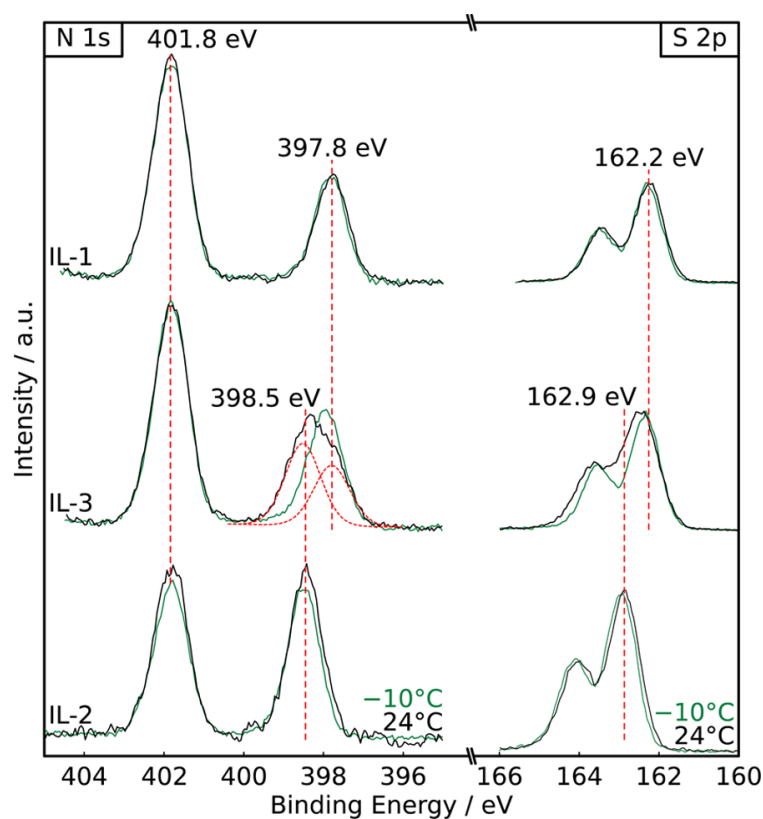

Figure 1. N 1s (left) and S 2p (right) region spectra of IL-1, IL-2, and IL-3 measured in normal emission at $24{ }^{\circ} \mathrm{C}$ (black) and at $-10{ }^{\circ} \mathrm{C}$ (green). The red lines show binding energy positions referenced to imidazolium nitrogen at $401.8 \mathrm{eV}$; moreover, deconvolution of the $\mathrm{N}$ 1s $[\mathrm{SCN}]^{-}$signal of IL-3 at $24{ }^{\circ} \mathrm{C}$ is shown as discussed in the text.

reported to the best of our knowledge. One should note that the here observed thiocyanate orientation might extend from the surface layer over several layers further into the bulk, which has been deduced for other IL systems by surface X-ray scattering $^{19}$ and molecular dynamic simulations; ${ }^{20}$ such an effect can, however, not be distinguished with ARXPS.

The ARXP spectra of IL- 2 at $24^{\circ} \mathrm{C}$ also exhibit an increase of $\sim 20 \%$ in the $S 2 p$ signal with increasing surface sensitivity, which is of similar magnitude as observed for IL-1; again, no change with cooling temperature is found (Figure S3). Because in the tetrahedrally coordinated complex no individual orientation of $[\mathrm{NCS}]^{-}$ligands is possible, the observed surface enrichment of sulfur in $80^{\circ}$ is attributed to the fact that three of the four ligands (that is, one of the tetrahedron's baseplanes) are preferentially oriented toward the vacuum side. For both neat ILs IL-1 and IL-2, further cooling does not lead to significant changes in peak positions or widths at normal and grazing emission. After solidification below $-60{ }^{\circ} \mathrm{C}$, charging effects could be observed by signal shifts toward higher binding energy and peak broadening (not shown).

The thiocyanate signals of the mixture IL- 3 at $24{ }^{\circ} \mathrm{C}$ are significantly broader than observed for IL-1 and IL-2. In particular, the anion $\mathrm{N}$ 1s level (black spectrum in Figure 1) clearly reveals two components, which can be described within the fitting uncertainty as a superposition of cobalt-bound thiocyanate in $\left[\mathrm{Co}(\mathrm{NCS})_{4}\right]^{2-}$ at $398.5 \mathrm{eV}$ and of free $[\mathrm{SCN}]^{-}$ at $397.8 \mathrm{eV}$, with an intensity ratio of $4: 3$ (see Figure 1), that is, with the nominal molar ratio expected for the IL-2/IL-1 1:3 mixture. The room-temperature S $2 p$ spectrum of IL-3 is also considerably broader than the corresponding spectra of the neat ILs IL-1 and IL-2, again due to the presence of species in two different chemical states. Note that due to spin-orbit splitting, the presence of two different species in the $S 2 p$ region is less obvious; however, deconvolution by peak fitting is fully in line with the results from the $\mathrm{N}$ 1s spectra of IL-3.
ARXPS at $24{ }^{\circ} \mathrm{C}$ shows again an increase in S $2 p$ intensity at $80^{\circ}$ (Figure S3 of the SI), similar to that of IL-1 and IL-2, indicating that at room temperature oriented free thiocyanate anions with sulfur pointing toward vacuum and $\left[\mathrm{Co}(\mathrm{NCS})_{4}\right]^{2-}$ anions are present in the outermost layers of IL-3.

In contrast with the neat ILs IL-1 and IL-2, moderate cooling of the mixture IL-3 to $-10{ }^{\circ} \mathrm{C}$, that is, still well above the color transition temperature of $-25{ }^{\circ} \mathrm{C}$, leads to a pronounced narrowing (25\% decrease in full width at half-maximum, fwhm) and intensity loss of the $[\mathrm{SCN}]^{-}$-related $\mathrm{N} 1 \mathrm{~s}$ and the $S 2 \mathrm{p}$ signals (green spectra of IL-3 in Figure 1) to fwhm values similar to those measured for IL-1, with binding energies of $398.0 \mathrm{eV}(\mathrm{N} 1 \mathrm{~s})$ and $162.4 \mathrm{eV}\left(\mathrm{S} 2 \mathrm{p}_{3 / 2}\right)$, respectively. The decrease in fwhms starts around $+20{ }^{\circ} \mathrm{C}$ and reaches the final narrow signals already at $+4{ }^{\circ} \mathrm{C}$, as it is evident from a slow cooling and heating cycle with $2{ }^{\circ} \mathrm{C}$ steps from +24 to $0{ }^{\circ} \mathrm{C}$ and back to $+24{ }^{\circ} \mathrm{C}$ (see N 1s spectra shown in Figure S4 of SI); the spectral changes in this cycle are fully reversible. Further cooling to even below the color transition temperature does not lead to any further spectral changes until freezing occurs at -75 ${ }^{\circ} \mathrm{C}$, as witnessed by film charging. Thus, at (and below) $4{ }^{\circ} \mathrm{C}$, the transition from the tetrahedral to the octahedral complex seems to have already occurred in the near-surface region probed by XPS, while in the bulk the transition only occurs at significantly lower temperatures. At $+4{ }^{\circ} \mathrm{C}$, beneath the XPS probing depth of $9 \mathrm{~nm}$, free $[\mathrm{SCN}]^{-}$and $\left[\mathrm{Co}(\mathrm{II})(\mathrm{NCS})_{4}\right]^{2-}$ anions are still present as clearly shown by the deep-blue color of the liquid film covering the sample holder. Interestingly, at $-10^{\circ} \mathrm{C}$ and below, only a very weak increase in the $\mathrm{S} 2 \mathrm{p}$ signals in $80^{\circ}$ emission is observed, as is evident from the ARXP spectra at -10 and $-30{ }^{\circ} \mathrm{C}$ in Figure S3 of the SI. Notably, at $-30{ }^{\circ} \mathrm{C}$, the IL-3 film on the sample holder has changed its color from blue to a red appearance, as witnessed by visual inspection.

Additional information on the transition from the tetrahedral to the octahedral cobalt complex can be deduced from the Co $2 p$ region of IL- 2 and IL-3. In Figure 2, normal emission Co $2 p$

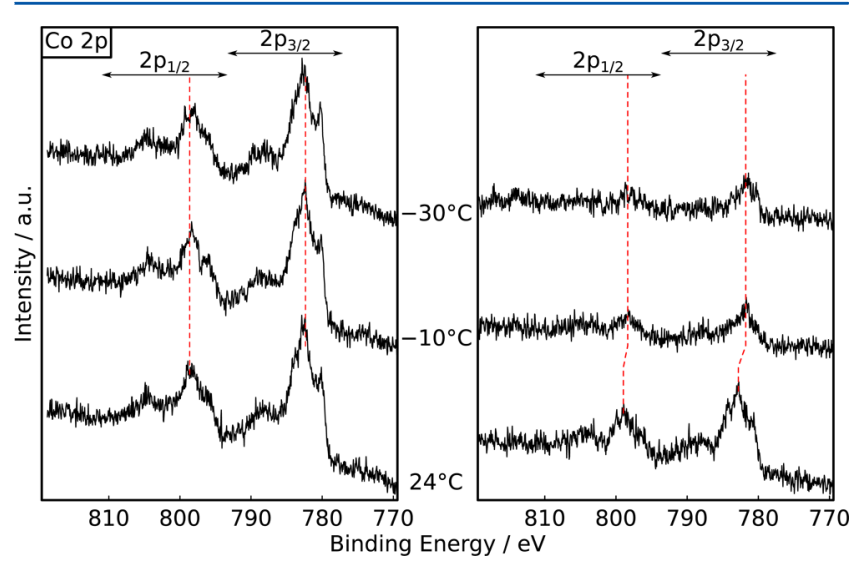

Figure 2. Co $2 \mathrm{p}$ spectra of IL-2 (left) and IL-3 (right), measured in normal emission. Because of the open-shell structure of the Co(II) complexes, multiplet splitting occurs for the $2 \mathrm{p}_{1 / 2}$ and $2 \mathrm{p}_{3 / 2}$ branches.

spectra of IL- 2 and IL-3 collected at $+24,-10$, and $-30^{\circ} \mathrm{C}$ are shown (without background subtraction). At $+24{ }^{\circ} \mathrm{C}$, both ILs exhibit spectra of identical shape, with the Co $2 \mathrm{p}_{1 / 2}$ branch between 810 and $795 \mathrm{eV}$, and the Co $2 \mathrm{p}_{3 / 2}$ branch between 795 and $778 \mathrm{eV}$; as expected for open-shell $\mathrm{Co}(\mathrm{II})$ systems, both branches exhibit multiplet splitting. At $24{ }^{\circ} \mathrm{C}$, the lower 
intensity (by $40 \%$ ) for IL-3 is due to the lower cobalt density in the mixture, as compared with IL-2.

Whereas the neat IL-2 does not reveal changes during cooling, the Co $2 p$ spectral shape of IL-3 is considerably altered at lower temperatures (see Figure 2): Whereas at room temperature the Co $2 \mathrm{p}_{1 / 2}$ branch of IL-3 shows one shoulder next to the peak maximum and the Co $2 \mathrm{p}_{3 / 2}$ branch shows two shoulders around the peak maximum, the intensity of these shoulders is considerably decreased at $-10{ }^{\circ} \mathrm{C}$. This change can most easily be quantified by differential shifts of the maxima in the $2 \mathrm{p}_{1 / 2}$ and $2 \mathrm{p}_{3 / 2}$ branches by about -0.6 and $-1.1 \mathrm{eV}$ to lower binding energy, respectively; the difference in shape is even more evident in Figure S5 of the SI, where the scaled spectra are plotted on top of each other for direct comparison. The change in apparent spin-orbit splitting and in spectral shape both clearly indicate a change in the complex structure. Because no further spectral changes occur when cooling IL-3 to $-30{ }^{\circ} \mathrm{C}$ (Figure 2) and below (see Figure S6), with the IL-3 film being fully red, we attribute the $-10^{\circ} \mathrm{C}$ spectrum shown in Figure 2 to the octahedral $\left[\mathrm{Co}(\mathrm{II})(\mathrm{NCS})_{6}\right]^{4-}$ complex being dominantly present in the near-surface region probed by XPS in normal emission. The observed overall Co $2 p$ shift toward lower binding energies is thus attributed to the increase in number of negatively charged $[\mathrm{NCS}]^{-}$ligands from 4 to 6 around the $\mathrm{Co}$ (II) core accompanied by a change in electron distribution; ${ }^{17}$ a reduction to $\mathrm{Co}(\mathrm{I})$ is extremely unlikely because $\mathrm{Co}(\mathrm{I})$ complexes typically can only be stabilized using multidentate or highly protective ligands, ${ }^{21}$ which is not the case for thiocyanate.

In addition to the change in shape of the Co $2 p$ spectra, we also observe a pronounced decrease in the overall Co $2 p$ signal upon cooling in Figure 2 to $\sim 40 \%$ of the original signal at 24 ${ }^{\circ} \mathrm{C}$ (overall intensity as derived by numerical integration from 770 to $815 \mathrm{eV}$ after linear background subtraction). We rule out beam damage effects because heating from $-10{ }^{\circ} \mathrm{C}$ back to room temperature fully restores the original Co $2 p$ intensity (not shown). The smaller Co $2 \mathrm{p}$ intensity indicates a decrease in density of the Co complex in the near-surface region contributing to the XPS signal. One possible explanation would be that in order to be stabilized at temperatures above the bulk transition temperature, the four times negatively charged octahedral $\left[\mathrm{Co}(\mathrm{II})(\mathrm{NCS})_{6}\right]^{4-}$ complex with its four imidazolium cations is solvated by additional $[\mathrm{SCN}]^{-}$anions. This configuration would lead to an excess of $[\mathrm{SCN}]^{-}$anions (including the corresponding cations) weakly bound to the octahedral complex in the near-surface region. Considering a solvation shell with, for example, 8 to 10 weakly bound $[\mathrm{SCN}]^{-}$ ions (instead of only one as expected from the stoichiometry of a $\left[\mathrm{C}_{2} \mathrm{C}_{1} \mathrm{Im}\right]_{4}^{+}\left[\mathrm{Co}(\mathrm{II})(\mathrm{NCS})_{6}\right]^{4-} /\left[\mathrm{C}_{2} \mathrm{C}_{1} \mathrm{Im}\right]^{+}[\mathrm{SCN}]^{-} 1: 1$ mixture), would be consistent with the pronounced decrease in the Co $2 p$ signal. The narrow line widths of the anion $\mathrm{N} 1$ s and $S$ $2 \mathrm{p}$ peaks in Figure 1 at $-10{ }^{\circ} \mathrm{C}$ furthermore indicate that the $\mathrm{N}$ $1 \mathrm{~s}$ and $\mathrm{S} 2 \mathrm{p}$ binding energies for the $\left[\mathrm{Co}(\mathrm{II})(\mathrm{NCS})_{6}\right]^{4-}$ and the free $[\mathrm{SCN}]^{-}$ions (that is, IL-1) are very similar. The proposed core-shell structure would also explain why, in contrast with IL-1, no pronounced surface orientation of free $[\mathrm{SCN}]^{-}$ions is observed below $4{ }^{\circ} \mathrm{C}$ because only $[\mathrm{SCN}]^{-}$ anions weakly bound to the octahedral complex are present in the near-surface region.

In conclusion, the observed temperature-dependent changes for IL-3 indicate that a complex transition from tetrahedrally toward octahedrally coordinated cobalt occurs in the nearsurface region until $+4{ }^{\circ} \mathrm{C}$, that is, at $\sim 30{ }^{\circ} \mathrm{C}$ higher temperature than in the bulk. The transition goes along with a pronounced decrease in the complex density in the nearsurface region, which is attributed to the formation of a weakly bound $[\mathrm{SCN}]^{-}$secondary solvation shell around the $[\mathrm{Co}(\mathrm{II})$ (NCS $\left.)_{6}\right]^{4-}$ anion, with a primary solvation shell of four cations, that is, an effective dilution of the complex. Without support from theory, we can only speculate about the driving force for the enhanced stability of the $\left[\mathrm{Co}(\mathrm{II})(\mathrm{NCS})_{6}\right]^{4-}$ complex in the near-surface region. One possibility could be related to the intrinsic potential of the IL/vacuum interface for inducing order in the near-surface region, as was witnessed, for example, by the preferential orientation of free $[\mathrm{SCN}]^{-}$anions at the surface observed by ARXPS (see above) or vertical layering effects found by other groups. ${ }^{19,20}$ If this ordering is reduced by the formation of the octahedral complex plus its extended solvation shell (as observed by us by the loss of free $[\mathrm{SCN}]^{-}$ orientation), and thus, if the reaction entropy in the nearsurface region is slightly higher than that in the bulk, where those ordering effects are absent, then a shift of the complex equilibrium (Scheme 1) is expected toward the right, which leads to the observed increase in transition temperature in the near-surface region. It is important to note that such surfaceinduced phenomena could be of high relevance for all concepts where high-surface-area materials are applied. While such effects are very difficult to discern using bulk analytic methods, we have demonstrated that for ionic-liquid-based systems surface-sensitive XPS allows access to such changes in detail.

\section{EXPERIMENTAL METHODS}

IL-1, $\left[\mathrm{C}_{2} \mathrm{C}_{1} \mathrm{Im}\right][\mathrm{SCN}]$, was purchased from IoLiTech (assay $>98 \%$, halides $<2 \%)$. IL-2, $\left[\mathrm{C}_{2} \mathrm{C}_{1} \mathrm{Im}\right]_{2}\left[\mathrm{Co}(\mathrm{NCS})_{4}\right]$, was purchased from KCT-Chemie UG. IL-3 with its nominal composition $\left[\mathrm{C}_{2} \mathrm{C}_{1} \mathrm{Im}\right]_{5}\left[\mathrm{Co}(\mathrm{NCS})_{4}\right][\mathrm{SCN}]_{3}$ was prepared by mixing IL-1 and IL-2 in a 3:1 molar ratio. Macroscopic samples (ca. $0.5 \mathrm{~mL}$ ) of the three ILs were placed onto molybdenum sample holders equipped with transferable thermocouples for accurate sample temperature readings and introduced to our new dual analyzer system for surface analysis ${ }^{22}$ (DASSA). The ILs were initially heated to $60^{\circ} \mathrm{C}$ for ca. $2 \mathrm{~h}$ under UHV (base pressure $2 \times 10^{-10} \mathrm{mbar}$ ) before scans were taken to drive off any remaining volatile components.

Once degassed, the samples were studied at room temperature $\left(24^{\circ} \mathrm{C}\right)$ and subsequently at $-10,-30,-60$, and $-75^{\circ} \mathrm{C}$, with survey and high-resolution scans at each temperature. Moreover, a cooling and heating cycle from room temperature to $0{ }^{\circ} \mathrm{C}$ and back was done for $\mathrm{IL}-3$ in $2{ }^{\circ} \mathrm{C}$ steps while recording XP spectra. All spectra were taken using a monochromated $\mathrm{Al} \mathrm{K} \alpha$ source. High-resolution scans used a pass energy of $35 \mathrm{eV}$ and a dwell time of $1.5 \mathrm{~s}$ with an overall energy resolution of $0.4 \mathrm{eV}$, while survey scans were recorded with a pass energy of $200 \mathrm{eV}$ and a dwell time of $0.5 \mathrm{~s}$. Angleresolved XPS (ARXPS) was done by recording spectra simultaneously with one analyzer mounted at $0^{\circ}$ (normal emission) and one mounted at $80^{\circ}$ (grazing emission), with respect to the surface normal. While $0^{\circ}$ electron emission is more bulk sensitive, with 7-9 $\mathrm{nm}$ information depth (depending on kinetic energy of the excited photoelectrons), emission at $80^{\circ}$ is about six times more surface sensitive, with 1 to $1.5 \mathrm{~nm}$ information depth.

Because of minor charging effects even at room temperature, the binding energy values of all spectra were referenced to the $\mathrm{N}$ 1s signal of the imidazolium cation being set to $401.82 \mathrm{eV}$, which is the value measured for IL-2 at room temperature. The 
nitrogen signal of the counterion was chosen because the imidazolium cation is expected to be least influenced by the complex reaction and provides a sharp and easily distinguishable signal. At temperatures below $-60{ }^{\circ} \mathrm{C}$, it was sometimes necessary to use an electron flood gun to counteract peak broadening by inhomogeneous charging when sample solidification occurred.

All imidazolium and ligand core levels could be fitted using simple Pseudo-Voigt functions (70\% Gaussian-30\% Lorentzian) after Shirley background subtraction.

\section{ASSOCIATED CONTENT}

\section{S Supporting Information}

The Supporting Information is available free of charge on the ACS Publications website at DOI: 10.1021/acs.jpclett.7b00142.

Setup used for monitoring color change of IL-3 as a function of temperature; thermochromic bulk behavior of IL-3 (frames from movie); $\mathrm{N}$ 1s and $\mathrm{S} 2 \mathrm{p}$ ARXP spectra of IL-1, IL-2, and IL-3 measured each at 24, -10 , and $-30{ }^{\circ} \mathrm{C}$; $\mathrm{N}$ 1s spectra of IL-3 during cooling and warming cycle; and Co $2 \mathrm{p}$ spectra of IL-3 at two different temperatures (rescaled) and at low temperatures (until $\left.-75^{\circ} \mathrm{C}\right)$. (PDF)

High-speed movie of the color change of IL-3 as a function of temperature (indicated by display); original duration from $-60{ }^{\circ} \mathrm{C}$ to $+7{ }^{\circ} \mathrm{C}: 19 \mathrm{~min}$. (AVI)

\section{AUTHOR INFORMATION}

\section{Corresponding Author}

*E-mail: florian.maier@fau.de.

\section{ORCID}

Hans-Peter Steinrück: 0000-0003-1347-8962

Florian Maier: 0000-0001-9725-8961

Notes

The authors declare no competing financial interest.

\section{ACKNOWLEDGMENTS}

B.M., F.G., R.B., and H.-P.S. thank the European Research Council (ERC) for financial support of this research in the context of the Advanced Investigator Grant "ILID" to H.-P.S.

\section{REFERENCES}

(1) Steinrück, H.-P.; Wasserscheid, P. Ionic Liquids in Catalysis. Catal. Lett. 2015, 145, 380-397.

(2) Walter, S.; Haumann, M.; Wasserscheid, P.; Hahn, H.; Franke, R. $\mathrm{n}$-Butane Carbonylation to n-Pentanal Using a Cascade Reaction of Dehydrogenation and SILP-catalyzed Hydroformylation. AIChE J. 2015, 61, 893-897.

(3) Carrasco, C. J.; Montilla, F.; Bobadilla, L.; Ivanova, S.; Odriozola, J. A.; Galindo, A. Oxodiperoxomolybdenum Complex Immobilized onto Ionic Liquid Modified SBA-15 as an Effective Catalysis for Sulfide Oxidation to Sulfoxides Using Hydrogen Peroxide. Catal. Today 2015, $255,102-108$.

(4) Malihan, L. B.; Nisola, G. M.; Mittal, N.; Lee, S.-P.; Seo, J. G.; Kim, H.; Chung, W.-J. SBA-15 Supported Ionic Liquid Phase (SILP) with H2PW12O40- for the Hydrolytic Catalysis of Red Macroalgal Biomass to Sugars. RSC Adv. 2016, 6, 33901-33909.

(5) Mehnert, C. P. Supported Ionic Liquid Phases. Chem. - Eur. J. 2005, 11, 50-56.

(6) Frost, D. C.; Ishitani, A.; McDowell, C. A. X-ray Photoelectron Spectroscopy of Copper Compounds. Mol. Phys. 1972, 24, 861-877.

(7) Frost, D. C.; McDowell, C. A.; Woolsey, I. S. X-ray Photoelectron Spectra of Cobalt Compounds. Mol. Phys. 1974, 27, 1473-1489.
(8) Briggs, D.; Gibson, V. A. Direct Observation of Multiplet Splitting in 2P Photoelectron Peaks of Cobalt Complexes. Chem. Phys. Lett. 1974, 25, 493-496.

(9) Niedermaier, I.; Kolbeck, C.; Taccardi, N.; Schulz, P. S.; Li, J.; Drewello, T.; Wasserscheid, P.; Steinrück, H.-P.; Maier, F. Organic Reactions in Ionic Liquids Studied by in situ XPS. ChemPhysChem 2012, 13, 1725-1735.

(10) Licence, P. In Situ XPS Monitoring of Bulk Ionic Liquid Reactions: Shedding Light on Organic Reaction Mechanisms. Angew. Chem., Int. Ed. 2012, 51, 4789-4791.

(11) Maier, F.; Cremer, T.; Kolbeck, C.; Lovelock, K. R. J.; Paape, N.; Schulz, P. S.; Wasserscheid, P.; Steinrück, H.-P. Insights into the Surface Composition and Enrichment Effects of Ionic Liquids and Ionic Liquid Mixtures. Phys. Chem. Chem. Phys. 2010, 12, 1905-1915.

(12) Lovelock, K. R. J.; Villar-Garcia, I. J.; Maier, F.; Steinrück, H.-P.; Licence, P. Photoelectron Spectroscopy of Ionic Liquid-Based Interfaces. Chem. Rev. 2010, 110, 5158-5190.

(13) Steinrück, H.-P. Recent Developments in the Study of Ionic Liquid Interfaces Using X-ray Photoelectron Spectroscopy and Potential Future Directions. Phys. Chem. Chem. Phys. 2012, 14, 5010-5029.

(14) Kolbeck, C.; Deyko, A.; Matsuda, T.; Kohler, F.; Wasserscheid, P.; Maier, F.; Steinrück, H.-P. Temperature-Dependent SurfaceEnrichment Effects of Imidazolium-Based Ionic Liquids. ChemPhysChem 2013, 14, 3726-3730.

(15) Niedermaier, I.; Bahlmann, M.; Papp, C.; Kolbeck, C.; Wei, W.; Krick Calderón, S.; Grabau, M.; Schulz, P. S.; Wasserscheid, P.; Steinrück, H.-P.; Maier, F. Carbon Dioxide Capture by an Amine Functionalized Ionic Liquid: Fundamental Differences of Surface and Bulk Behavior. J. Am. Chem. Soc. 2014, 136, 436-441.

(16) Peppel, T.; Köckerling, M.; Geppert-Rybczyńska, M.; Ralys, R V.; Lehmann, J. K.; Verevkin, S. P.; Heintz, H. Low-Viscosity Paramagnetic Ionic Liquids with Doubly Charged $\left[\mathrm{Co}(\mathrm{NCS})_{4}\right]^{2-}$ Ions. Angew. Chem., Int. Ed. 2010, 49, 7116-7119.

(17) Osborne, S. J.; Wellens, S.; Ward, C.; Felton, S.; Bowman, R. M.; Binnemans, K.; Swadzba-Kwasny, M.; Gunaratne, H. Q. N.; Nockemann, P. Thermochromism and Switchable Paramagnetism of Cobalt(II) in Thiocyanate Ionic Liquids. Dalton Trans. 2015, 44, 11286-11289.

(18) McCourt, E.; Wojnarowska, Z.; Jacquemin, J.; Nockemann, P.; Manyar, H. G.; Hawelek, L.; Paluch, M. Temperature- and PressureInduced Structural Changes of Cobalt(II) in a Phosphonium-Based Ionic Liquid. J. Phys. Chem. C 2016, 120, 10156-10161.

(19) Mezger, M.; Ocko, B. M.; Reichert, H.; Deutsch, M. Surface Layering and Melting in an Ionic Liquid Studied by Resonant Soft Xray Reflectivity. Proc. Natl. Acad. Sci. U. S. A. 2013, 110, 3733-3737.

(20) Amith, W. D.; Hettige, J. J.; Castner, E. W.; Margulis, C. J. Structures of Ionic Liquids Having Both Anionic and Cationic Octyl Tails: Lamellar Vacuum Interface vs Sponge-Like Bulk Order. J. Phys. Chem. Lett. 2016, 7, 3785-3790.

(21) Hicks, J.; Jones, C. Low-Coordinate Cobalt(I) Complexes Stabilized by an Extremely Bulky Amide Ligand. Organometallics 2015, $34,2118-2121$.

(22) Niedermaier, I.; Kolbeck, C.; Steinrück, H.-P.; Maier, F. Dual Analyzer System for Surface Analysis Dedicated for Angle-Resolved Photoelectron Spectroscopy at Liquid Surfaces and Interfaces. Rev. Sci. Instrum. 2016, 87, 045105 .

\section{NOTE ADDED AFTER ASAP PUBLICATION}

This paper was published ASAP on February 23, 2017. The abstract graphic was updated. The revised paper was reposted on February 24, 2017. 